\title{
Pulsatile release of oxytocin into the circulation of the ewe during oestrus, mating and the early luteal phase
}

\author{
C. L. Gilbert*, K. Jenkins and D. C. Wathes* \\ Department of Anatomy, University of Bristol School of Medical Sciences, Bristol BS8 1TD, UK
}

\begin{abstract}
Summary. Two experiments were designed to investigate release patterns of oxytocin into plasma during oestrus and the early luteal phase. In Exp. 1, blood samples were collected from 5 ewes every $30 \mathrm{~min}$ for $10 \mathrm{~h}$ during 6 days around oestrus and the early luteal phase. During oestrus concentrations of oxytocin were generally low $(1.27 \pm 0.54 \mathrm{pg} / \mathrm{ml}$; mean \pm s.d.) but with occasional pulses up to $6 \mathrm{pg} / \mathrm{ml}$. By Day 5 mean basal concentrations had risen to $4 \cdot 5 \pm 2 \cdot 1 \mathrm{pg} / \mathrm{ml}$ with a fluctuating release pattern.

In Exp. 2, a method was developed for continuous blood sampling from conscious, unrestrained ewes. On the predicted day of oestrus following an untreated oestrous cycle, $8-\mathrm{ml}$ blood samples were collected every minute for two 35 -min periods ( 8 ewes: 16 sampling periods). For 6 ewes a ram was introduced to the pen for part of this time, and resulting behaviour was recorded. Additional blood samples were assayed for LH and progesterone to determine the stage of the cycle. Overall mean oxytocin concentrations ranged from $1.5 \pm 0.53$ to $6 \cdot 8 \pm 5 \cdot 25 \mathrm{pg} / \mathrm{ml}$ in different animals. Ewes which were both in oestrus and exposed to the ram showed a pulsatile oxytocin release pattern consisting of low baseline concentrations with short-duration pulses superimposed (duration 1-4 min; amplitude $2 \cdot 5-31 \cdot 7 \mathrm{pg} / \mathrm{ml}$; frequency $3 \cdot 18 / \mathrm{h}$ ). Coitus was not temporally associated with pulsatile release. However, the importance of the presence of the ram was indicated by total separation of 2 oestrous ewes from the ram until after experimentation. In these animals only 1 pulse of oxytocin was detected in $2.7 \mathrm{~h}$ of sampling.

It is concluded that, although mean oxytocin concentrations at oestrus were low, short duration pulses were released into the plasma at this time. This effect may be dependent on the presence of a ram.
\end{abstract}

Keywords: oxytocin; oestrus; ewe; coitus

\section{Introduction}

The pulsatile nature of oxytocin and neurophysin release into the bloodstream during luteolysis in the ewe has been extensively researched (for review see Wathes, 1989). Much less is known about oxytocin release during oestrus and the early luteal phase. Published reports (Sheldrick \& Flint, 1981; Webb et al., 1981; Schams et al., 1982b; Wathes et al., 1986) agree that a nadir in circulating concentrations of oxytocin occurs at oestrus, but relatively infrequent blood sampling regimens have prevented more detailed characterization. By contrast, oxytocin binding studies have shown receptor numbers to be maximal at oestrus and to remain relatively high into the early luteal phase in uterine endometrium and myometrium (Roberts et al., 1976; Sheldrick \& Flint, 1985; Ayad \& Wathes, 1989) and whole oviduct membrane preparations (Ayad et al., 1990a). There is therefore a

*Present address: AFRC Institute of Animal Physiology and Genetics Research, Babraham Hall, Babraham, Cambridge CB2 4AT, UK. 
paradox between a receptive reproductive tract at oestrus and low reported circulating oxytocin concentrations at this time.

The half-life of oxytocin in blood is reported to be short in the ewe $(29 \mathrm{sec}$ : Barowicz \& Styczynski, 1972, using bio-assay methods) and the rat (1.46 min: Higuchi et al., 1985, using radioimmunoassay). This permits the hypothesis that short-duration pulsatile release patterns of oxytocin may occur which were unrecorded by previous workers with the exception of the preliminary study of Mitchell et al. (1982). In addition, there is considerable controversy over the ability of coitus to induce oxytocin release in female mammals (Jochle, 1975; Forsling, 1986). Although vaginal distension using pressure balloons was effective in inducing oxytocin release in sheep (Roberts \& Share, 1969) and cattle (Schams et al., 1982a), mating itself has produced more equivocal results. Garcia-Villar et al. (1985) could find no release of oxytocin during mating in sheep using a radioimmunoassay on plasma collected from restrained ewes and this agreed with the results of Schams et al. (1982a) for cattle. However, McNeilly \& Ducker (1972) showed that more subtle psychogenic effects such as auditory, visual and olfactory stimuli between male and female goats could stimulate oxytocin release, suggesting the importance of normal and uninhibited behavioural interactions before mating.

The present studies were designed (1) to characterize release patterns of oxytocin from ewes during the oestrous and early luteal phases and (2) to examine in more detail the release of oxytocin during behavioural oestrus under conditions of minimal interference, and to assess the influence of the presence of a ram and coitus upon this.

\section{Materials and Methods}

Animals. Mature Clun Forest ewes were used in the breeding seasons of 1987 and 1988 when the animals were undergoing normal oestrous cycles. At 1 week before experimentation, ewes were housed in individual pens $1.5 \mathrm{~m}^{2}$ and fed hay and a concentrate mix daily with water always available.

Experiment 1. Initially, 10 ewes at pasture were given an intravaginal progesterone sponge (Veramix: Upjohn Ltd, Crawley, West Sussex, UK) for 12 days. After sponge removal the ewes were run with a vasectomized ram fitted with a raddle. Five ewes which were all in oestrus and mated 2 days after sponge removal were selected.

At 15 days after oestrus, these 5 ewes were all fitted with a jugular cannula (Portex: 16-gauge Luer lock) according to the method of Seldinger (1953). A blood sample was taken at 19:00 h on this day and subsequently every $5 \mathrm{~h}$ for the next $53 \mathrm{~h}$. The blood was centrifuged and plasma samples stored at $-20^{\circ} \mathrm{C}$ for later RIA for luteinizing hormone (LH).

In addition, for 6 consecutive days beginning at 16 days after oestrus, blood samples $(8 \mathrm{ml})$ were taken every $30 \mathrm{~min}$ for $10 \mathrm{~h}$ of each day, from 09:00 to 19:00 h. The blood was cooled rapidly on ice, centrifuged for $10 \mathrm{~min}$, and an aliquant of plasma $\left(4 \mathrm{ml}\right.$ ) was acidified with $0.25 \mathrm{ml} 0.1 \mathrm{M}-\mathrm{HCl}$, snap frozen on solid $\mathrm{CO}_{2}$ and stored at $-20^{\circ} \mathrm{C}$ for subsequent assay for oxytocin. Daily plasma samples were taken for progesterone RIA.

A vasectomized ram was used 2-3 times a day to assess behavioural oestrus in each ewe. When not in use the ram was kept out of visual contact with ewes but was within the same airspace.

Experiment 2. Eight ewes, identified by letters A, E, F, G, J, K, L and M, were fitted with intravaginal progesterone sponges as above except for Ewe A (see below). The sponges were inserted for 13 days and the ewes checked for oestrus over the ensuing 4 days by using a vasectomized ram fitted with a raddle. A complete oestrous cycle was then allowed with no hormonal interference and experiments were performed at the next oestrus, 16 or 17 days after raddling.

Ewe A was brought into oestrus using two injections of the prostaglandin F-2 $\alpha$ analogue cloprostenol $(400 \mu 1$ Estrumate: Coopers Animal Health, Crewe, Cheshire, UK) given intramuscularly 10 days apart, with oestrus occurring 3 days after the second injection.

Experimental design and continuous blood-sampling technique. On the day of experimentation, each ewe was fitted with an indwelling jugular cannula and blood samples were taken every $30 \mathrm{~min}$ for $10 \mathrm{~h}$ for subsequent oxytocin assay as in Exp. 1. In addition, for two 35-45-min periods for each ewe (on the same day, but at least $3 \mathrm{~h}$ apart), blood (6$8 \mathrm{ml} / \mathrm{min}$ ) was continuously withdrawn from the jugular cannula and collected in aliquants representing flow for I min. This was achieved by connecting the cannula to a length of Silastic tubing (Dow Corning: i.d. $1.5 \mathrm{~mm}$ ) via a double male Luer lock connector (Vygon (U.K.) Ltd, Cirencester, Gloustershire, UK). The tubing was passed through the centre of a long loose spring which was hooked above the pen at one end and tied to the ewe's neck bandage at the other. The cannula led to a peristaltic pump and fraction collector system (Retriever II; Isco, Life Science Laboratories, Luton, Beds, UK). Each ewe was given 4000 i.u. heparin sodium (Evans Medical Ltd, 
Greenford, Middlesex, UK) $15 \mathrm{~min}$ before the start of this procedure. In this way it was possible to withdraw blood continuously from an unrestrained animal in the familiar surroundings of its own pen. These blood samples were treated as above and stored for later oxytocin assay, and plasma taken from 2 ewes (E and $G$ ) during continuous collection was also assayed for arginine vasopressin (AVP).

For 6 ewes (all except Ewes $L$ and $M$ ), a ram was introduced into the ewe's pen after 10 min of continuous blood collecting and allowed to remain for 15-20 min, during which time any behavioural interactions were noted. Blood collection continued for $10 \mathrm{~min}$ after the ram's removal. When not in use the ram was kept in a separate pen some $10 \mathrm{~m}$ from the experimental area, out of sight of the ewes but within the same room. At least 2 other ewes were always present in pens adjacent to the experimental area in visual, auditory and olfactory contact.

By contrast, Ewes $L$ and $M$ were not permitted contact of any sort with a ram until immediately after continuous bleeding (Ewe L) or given first exposure to olfactory and visual contact only during the second continuous bleed (Ewe M) followed by free access after blood collection to check for behavioural oestrus.

Daily blood samples $(6 \mathrm{ml})$ were taken throughout for plasma progesterone assay. In addition, blood samples were taken very $5 \mathrm{~h}$ for $45 \mathrm{~h}$ around the time of expected oestrus and plasma stored at $-20^{\circ} \mathrm{C}$ for $\mathrm{LH}$ assay. Blood for $\mathrm{LH}$ assay was not collected from Ewes $\mathrm{L}$ and $\mathrm{M}$.

Oxytocin RIA. Plasma oxytocin measurements were made after extraction of plasma on C18 Bond elut cartridges (Analytichem International, Harbor City, CA, USA). These mini-columns were primed as described previously (Wathes et al., 1986) and a vacuum manifold was used to control and standardize a slow fluid flow-rate, within the recommendations of Higa \& Desiderio (1989). The extraction efficiency was $81 \%$. The assay was performed as described by Wathes et al. (1986) using the antiserum 85/2, raised and characterized by Dr J. Fletcher in the Department of Anatomy, University of Bristol. This antiserum cross-reacts $32 \%$ with mesotocin, but $<0 \cdot 1 \%$ with lysine vasopressin, arginine vasopressin, arginine vasotocin or neurophysin I and II. The sensitivity of the assay was equivalent to $0.5 \mathrm{pg} / \mathrm{ml}$ plasma, and inter-and intra-assay co-efficients of variations were $14 \cdot 1$ and $10 \cdot 4 \%$ respectively.

LH RIA. Plasma LH concentrations were assayed using the specific double-antibody radioimmunoassay of Foster \& Crighton (1974) as modified by McLeod et al. (1982). The limit of sensitivity was $0.25 \mathrm{ng}$ NIH-LH-S24 equiv./ml plasma and the intra-assay co-efficient of variation was $9 \cdot 4 \%$. LH data for individual ewes were always derived from results within one assay.

Progesterone RIA. Plasma samples $(0.25 \mathrm{ml})$ were extracted and assayed for progesterone as described previously (Wathes et al., 1986). The minimum detectable dose was $0.1 \mathrm{ng} / \mathrm{ml}$, and inter- and intra-assay co-efficients of variation 12.4 and $10.4 \%$ respectively.

Arginine vasopressin RIA. Measurements were made on the same extracts used for the oxytocin assay, using the specific radioimmunoassay described previously by Wathes et al. (1983), using an antiserum (84/1) raised and characterized in the Department of Anatomy. This antiserum cross-reacts $<6 \%$ with lysine vasopressin and arginine vasotocin, and $<0.03 \%$ with oxytocin, mesotocin, and the neurophysins. The minimum detectable dose was equivalent to $0.1 \mathrm{pg} / \mathrm{ml}$ plasma and the intra-assay variation was $10 \%$.

Statistical analysis. The continuous plasma oxytocin profiles were analysed for the presence of statistically significant episodes of release using the computer programme, "Munro" (Taylor, 1987), which is an adapted version of the pulse analysis method of Merriam \& Wachter (1982). The number of samples used for the floating window to determine the baseline of the profiles from which pulses were calculated was 25 . The number of standard deviations above this baseline which were required to define a pulse was $3.98,2.40,1.68,1.24$ and 0.93 for every assay point in peaks of $1-5$ points respectively.

\section{Results}

\section{Experiment 1}

All 5 ewes experienced an LH surge during the 53-h blood-sampling period, the timing of these surges being in good agreement with individual progesterone profile data. In addition, all animals were in behavioural oestrus during the experiment, as judged by their mating behaviour with the vasectomized ram. All LH surges occurred within $16 \mathrm{~h}$ of the start of behavioural oestrus.

Plasma profiles for progesterone and oxytocin (derived from mean data from all ewes undergoing the 30-min bleeding regimen) are shown in Fig. 1. Relatively high hormone concentrations were seen during luteolysis, descending to a nadir coincident with the LH surge, followed by a gradual rise over the ensuing days. The standard deviations shown reflect considerable variability in oxytocin output throughout this time; for example, individual values during the day of the $\mathrm{LH}$ surge ranged from 0.5 to $6 \mathrm{pg} / \mathrm{ml}$. 


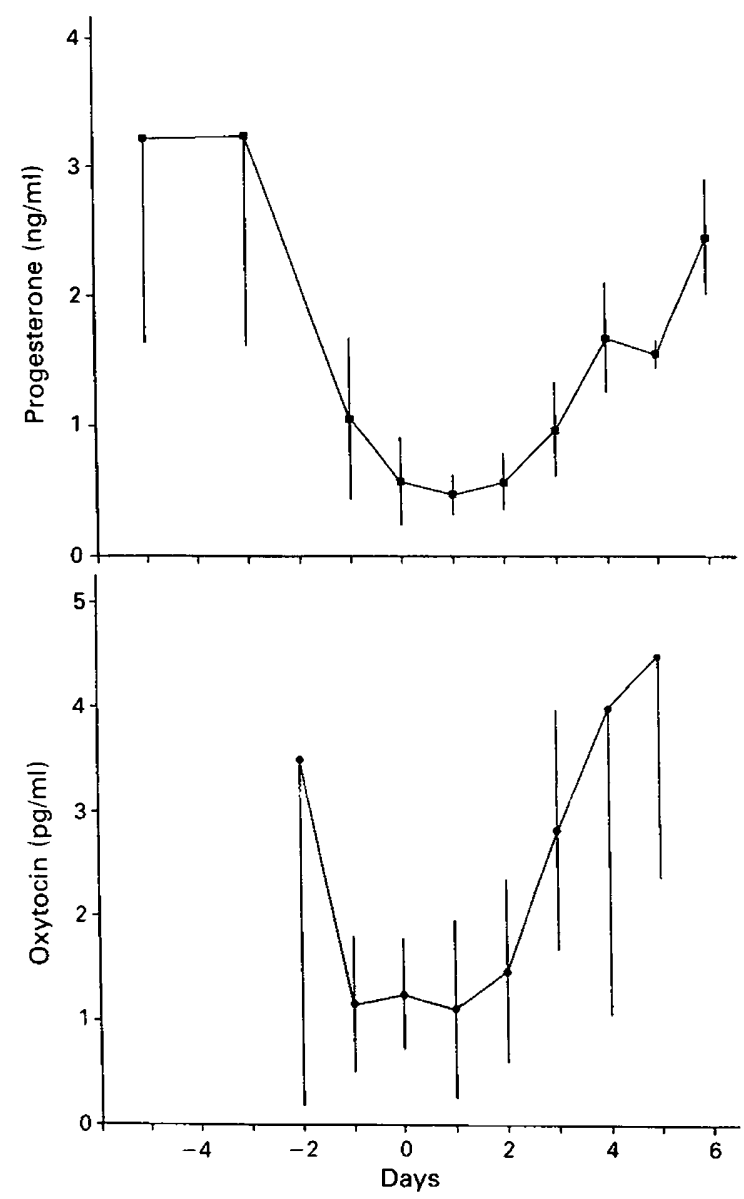

Fig. 1. Mean \pm s.d. progesterone $(\boldsymbol{D})$ and oxytocin $(\Theta)$ concentrations for the 5 ewes used in Exp. 1. Day $0=$ day of the LH surge. Number of determinations for each point $=3-5$ (progesterone) and 50-105 (oxytocin).

Individual oxytocin profiles derived from the blood samples taken at 30 -min intervals on each experimental day for 2 representative ewes are shown in Fig. 2. In 2 ewes (not illustrated) a relatively late LH surge resulted in blood sampling during luteolysis and characteristic peaks of up to $37 \mathrm{pg} / \mathrm{ml}$ with a duration of up to $2.5 \mathrm{~h}$ were present. On the day of the LH surge, a low but variable oxytocin release profile was seen in all ewes, and in the next few days profiles consisted of a gradually elevating baseline and the appearance of more obvious superimposed pulsatile activity.

\section{Experiment 2}

The animals were divided into 3 groups according to the stage of the cycle that they were experiencing when subjected to continuous blood sampling. This was judged on the basis of daily progesterone and 5-h LH measurements, and on behavioural interactions with the ram.

Examples of oxytocin profiles obtained from the continuous sampling periods from ewes in each group are shown in Fig. 3. Group 1 consisted of 2 ewes (E and G) in which plasma LH and progesterone profiles suggested that they were in the early follicular phase before the LH surge. Ewe $\mathrm{E}$ was mated once during each continuous sampling period but Ewe $\mathrm{G}$ did not display behavioural oestrus during experimentation. Both of these ewes were slaughtered $40 \mathrm{~h}$ after the second 
EWE 1

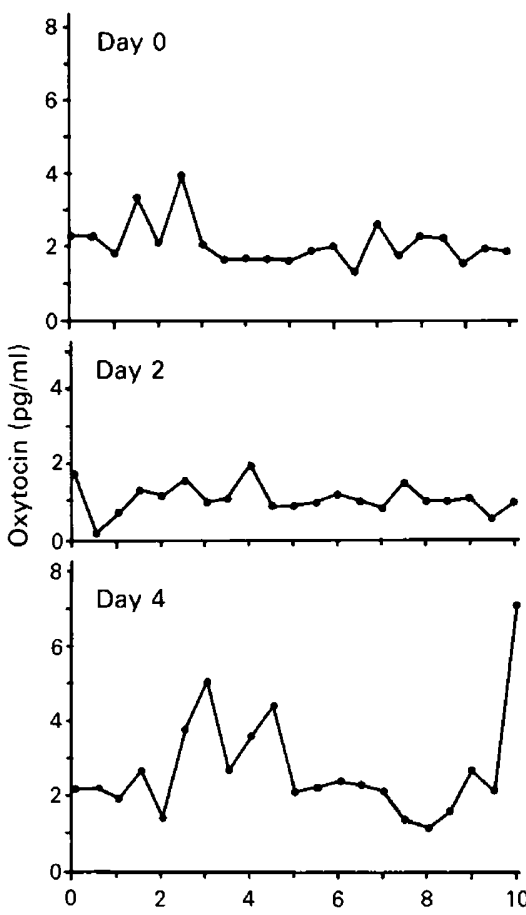

EWE 2
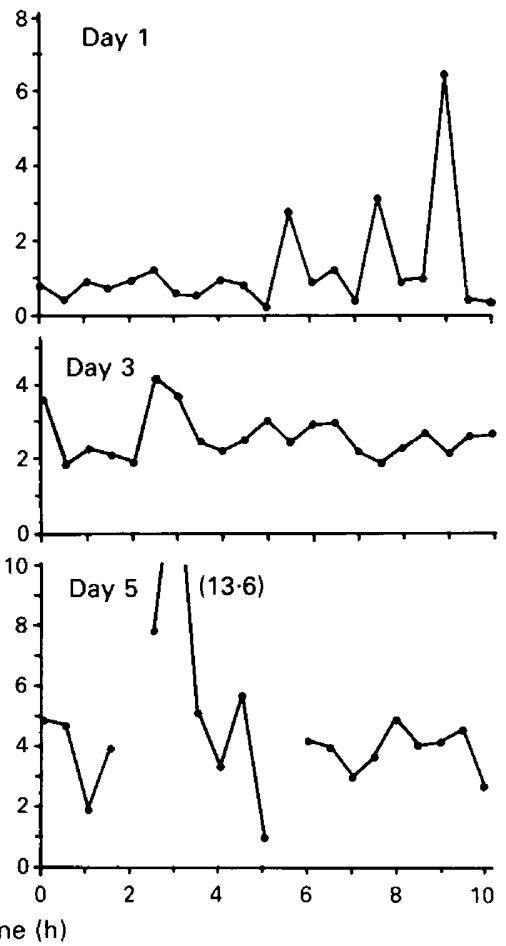

Fig. 2. Profiles of jugular plasma oxytocin concentrations derived from 2 representative ewes from Exp. 1. Blood samples in the graphs illustrated were taken every $30 \mathrm{~min}$ for $10 \mathrm{~h} /$ day on Days 0, 2 and 4 (Ewe 1) and 1, 3, and 5 (Ewe 2) relative to the LH surge. These examples show that, whilst mean plasma oxytocin increased gradually during this period, pulsatile release patterns were also present.

blood sampling session and the ovaries still contained large unruptured follicles. The 30-min samples from Ewe G showed a $2 \cdot 5$-h pulse of oxytocin release that was consistent with late luteolysis (Flint \& Sheldrick, 1983; Hooper et al., 1986). Neither of these animals showed any short-duration pulsatile oxytocin release during continuous sampling (Fig. 3).

Group 2 consisted of Ewes J, K, A and F which were all sampled for continuous plasma oxytocin concentrations within $12 \mathrm{~h}$ of the $\mathrm{LH}$ surge. These animals were all in behavioural oestrus and mated during the experiment, Ewes $\mathbf{F}$ and $\mathbf{J}$ during both sampling periods and Ewes $\mathbf{A}$ and $\mathbf{K}$ during only one. The 4 animals experienced a total of 15 significant pulses $(P<0.05)$ at a mean pulse rate of $3 \cdot 18 / \mathrm{h}$ (Fig. 3).

The timing of these pulses relative to the presence of the ram is shown in Table 1. There was no apparent alteration in pulse frequency associated with the presence of the ram in the pen when compared with before or after this time.

During the $133 \mathrm{~min}$ in which the ram was in the pen of a Group 2 ewe during blood sampling, mating occurred 13 times with the various ewes. None of these events was exactly coincident with any of the 7 oxytocin pulses which occurred during this time, although on two occasions a pulse occurred within 2 min after mating.

Group 3 consisted of Ewes $\mathrm{L}$ and $\mathrm{M}$. These 2 animals were kept completely apart from a ram before and during experimentation, except for the final part of bleed 2 for Ewe $\mathbf{M}$ in which visual, olfactory and auditory contact only through cage bars was permitted. This was in contrast to the animals in Groups 1 and 2 which had olfactory and auditory contact with a ram throughout, plus complete physical contact at the times specified. Ewes $\mathrm{L}$ and $\mathrm{M}$ were both shown to be in full 

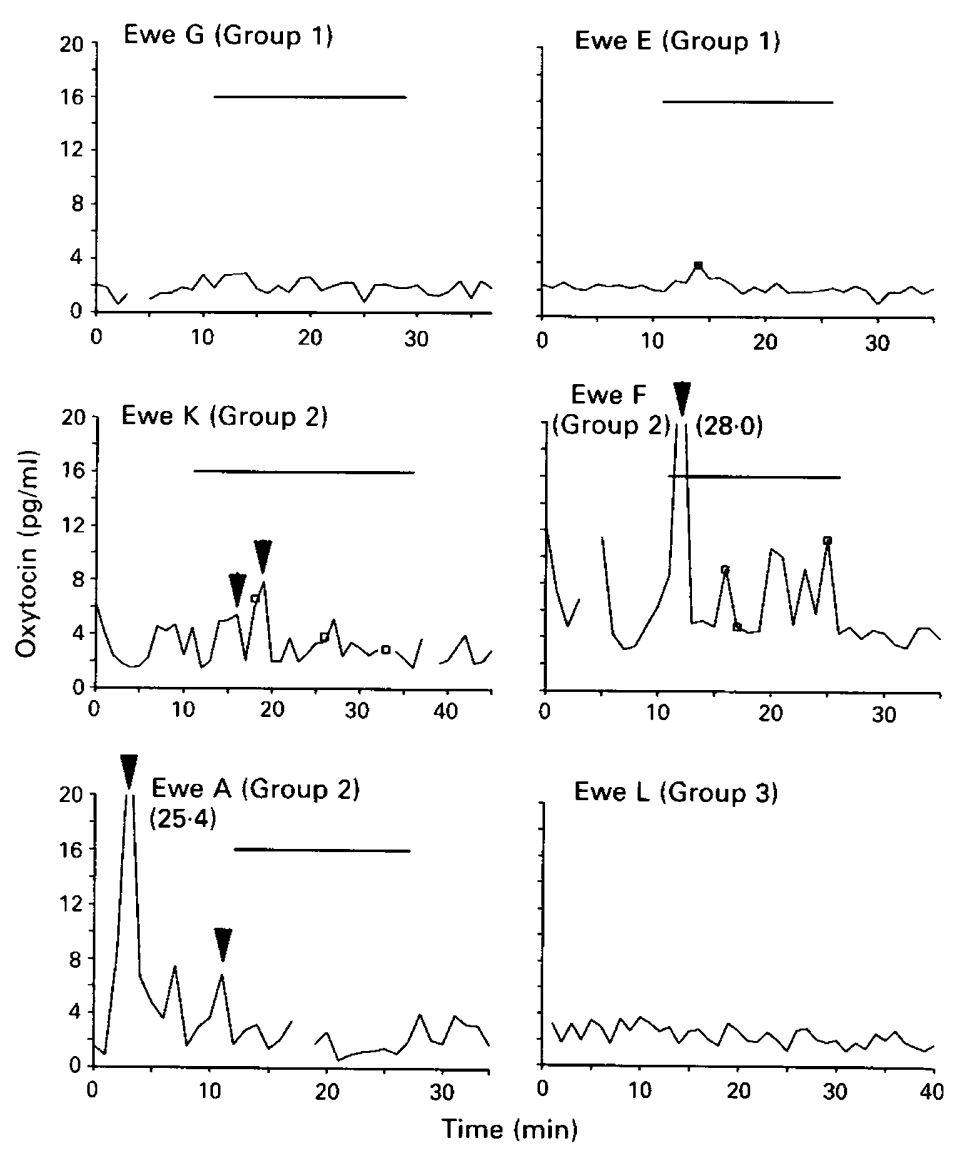

Fig. 3. Profiles of jugular plasma oxytocin concentrations derived from continuous blood sampling of 6 representative ewes from Exp. $2 . \boldsymbol{V}=$ significant $(P<0.05)$ pulse of plasma oxytocin; the solid bar indicates the presence of a ram in the recording pen (kept in an adjacent pen at other times); $\square=$ mating observed. Ewes $G$ and $E$ were in the follicular phase at least $10 \mathrm{~h}$ before the LH surge when sampled (Group 1), and displayed no or very reluctant oestrous behaviour with a ram and no pulsatile oxytocin release. Ewes $\mathrm{K}, \mathrm{F}$ and $\mathrm{A}$ were sampled $2 \mathrm{~h}$ before, during and $24 \mathrm{~h}$ after the LH surge respectively and displayed oestrous behaviour (Group 2). These animals released significant pulses of oxytocin into the plasma. Ewe L showed overt oestrus and was mated immediately after sampling but was separated from all contact with a ram until then (Group 3). No pulses occurred during this sampling period.

standing oestrus by mating with a ram immediately after experimentation and plasma progesterone results were consistent with behavioural indicators. Blood samples for plasma LH were not taken. Apart from one low pulse from Ewe L, neither animal showed significant fluctuations in oxytocin concentrations during continuous bleeding (Fig. 3). Greater variability in results was noted in Ewe $M$ after ram contact was permitted, but this did not reach significance.

Results from AVP RIA of plasma from continuous blood collection from 2 ewes were all $<2 \cdot 2 \mathrm{pg} / \mathrm{ml}$. There was no increase in mean AVP concentrations during the sampling period, indicating that plasma AVP was unaltered by the withdrawal of $300 \mathrm{ml}$ blood over $35 \mathrm{~min}$.

\section{Discussion}

The combined results of Exp. 1 represent the largest sampling regimen of its type within one laboratory and support previous evidence that overall oxytocin output into ewe plasma is at its lowest at 
Table 1. Timing of plasma oxytocin pulses in the 4 Group-2 ewes* in Exp. 2, relative to the presence of a ram $\dagger$

\begin{tabular}{lcc}
\hline $\begin{array}{l}\text { Presence of } \\
\text { ram in pen }\end{array}$ & No. of pulses & Pulse rate/h \\
\hline Before & 5 & 3.41 \\
During & 7 & 3.16 \\
After & 3 & 2.90 \\
Total & 15 & 3.18 \\
\hline
\end{tabular}

*Animals in oestrus and exposed to a ram during blood sampling. Ewes which fulfilled only one of these criteria (Groups 1 and 3 respectively) produced a total of only 1 pulse between them.

†Ewes were continuously blood sampled for $35-45 \mathrm{~min}$, during which time a ram was introduced (except for Group 3) for $15 \mathrm{~min}$.

the time of the LH surge (Sheldrick \& Flint, 1981; Webb et al., 1981; Schams et al., 1982b; Wathes et al., 1986). There was considerable variability in these reports as to actual concentrations in individual ewes. This may in part be accounted for by the different assays used, particularly the different antisera and extraction techniques employed. However, it may also be suggested from the results of Exp. 2 (see below) that the proximity of the ram at the time of sampling may be important.

Patterns of oxytocin release in Exp. 1 during luteolysis consisted of pulses of oxytocin lasting $0.5-2.5 \mathrm{~h}$ superimposed upon a low baseline output. This is consistent with previous reports of oxytocin pulses at this time in sheep (Flint \& Sheldrick, 1983) and cattle (Vighio \& Liptrap, 1986). At oestrus jugular vein oxytocin concentrations were often low but only 6 of 100 measurements fell below assay sensitivity $(0.5 \mathrm{pg} / \mathrm{ml})$ and concentrations fluctuated up to a maximum of $6 \mathrm{pg} / \mathrm{ml}$. After the LH surge the baseline jugular plasma oxytocin concentration gradually increased between Days 0 and 4 of the oestrous cycle and a fluctuating pattern of release emerged, although this was less marked than that during luteolysis. This output probably reflects a growing capacity for oxytocin synthesis from the new enlarging corpus luteum, with gene expression triggered by ovulation (Ivell et al., 1985). The factors controlling oxytocin release from the newly formed CL remain unclear (for review see Wathes, 1989).

Experiment 2 demonstrates the successful use of a novel technique for continuous blood sampling from sheep. One or more short-duration pulses of oxytocin, as detected objectively by computer programme, were seen in 6 of 8 ewes tested. This phenomenon was also observed by Mitchell et al. (1982) in 2 ewes and in a preliminary report by McCracken et al. (1984). The rapid decline in plasma oxytocin concentrations after an episode of release may be accounted for by the short half-life (Barowicz \& Styczynski, 1972) and/or peripheral dilution of the bolus.

In the present experiments, only the 4 animals in Group 2 which were sampled while in behavioural oestrus, with a ram present, and within $12 \mathrm{~h}$ of the $\mathrm{LH}$ surge, showed an obvious short duration pulsatile release pattern. However, these pulses did not appear to be associated with mating itself. Animals sampled in the follicular phase in the presence of a ram (Group 1) or in oestrus but in the absence of a ram (Group 3) showed only one pulse of oxytocin in 4 sampling periods for each group. The ewes in Groups 1 and 2 were in constant olfactory, visual and auditory contact with a ram and also with other females (analogous to the flock environment), suggesting that the different results may be accounted for by different phases of the cycle. However, the ewes in Group 3, although shown to be in oestrus immediately after experimentation, were up to then kept as isolated individuals. Behavioural cues may therefore account for the difference between their 
oxytocin release patterns and those of Group 2. Overall, this suggests that both the phase of the oestrous cycle and the presence of a ram are important for the observed responses.

Although this suggestion is derived from a relatively small number of animals per group, there is some support from the literature. McNeilly \& Ducker (1972) found that in female goats oxytocin release detected by bioassay occurred at oestrus but that behavioural cues such as the presence of another goat (of either sex) were more important in producing oxytocin release than the physical stimuli of coitus. In ewes the literature investigating responses to mating is less revealing. Hawker $e t$ al. (1959) were unable to measure significant differences in circulating oxytocin (as measured by bioassay) before and after coitus in 5 oestrous ewes, although these results represented only 2 blood samples per ewe. Roberts \& Share (1969) showed that vaginal distension with an air-filled balloon increased circulating oxytocin concentrations but did not specify the stage of the cycle or the presence of a ram. In a more detailed experiment Garcia-Viller et al. (1985) took regular blood samples before, during and after mating in 4 ewes and found that overall mean values for plasma oxytocin were not significantly altered. However, these authors did not present profiles of release from individual ewes.

Data from experiments in other species (cattle: Van Demark \& Hays, 1953; Debackere \& Peeters, 1960; Schams et al., 1982a; rabbit: Fuchs et al., 1981; Todd \& Lightman, 1986; pigs: Mattioli et al., 1986; man: Fox \& Knaggs, 1969; Carmichael et al., 1987) reveal a general consensus that it is possible to induce oxytocin release in a variety of female mammals during the oestrous period. However, the stimulus for release is not consistent between experiments in that vaginal manipulation will generally elicit release whereas coitus is less reliable, particularly in cattle. Overall, the precise stimulus for oxytocin release at oestrus remains unknown, but is possibly a combination of physical and psychogenic stimuli with considerable species variation. In the present experiments with sheep, although the presence of other sheep, particularly a ram, was important to produce the observed effects, there was no clear correlation between vaginal stimulation produced by coitus and oxytocin concentrations.

The origin of plasma oxytocin at oestrus also remains unknown. However, if the hypothesis of a psychogenic basis for release is accepted, the pituitary seems a more likely source than the ovary, particularly as oxytocin content of the ovary at oestrus is low in ewes and cows (Wathes et al., 1984, 1986). In addition, the experiments quoted above evoking oxytocin release at oestrus by vaginal distension resemble work using animals both near parturition (Flint et al., 1975), and during lactational anoestrus (Debackere et al., 1961), when ovaries have minimal oxytocin contents. Furthermore, pulsatile oxytocin release has been postulated in oestrogen-stimulated ovariectomized ewes (Lamsa \& McCracken, 1985).

The release of oxytocin described in Exp. 2 coincides with maximal concentrations of oxytocin receptors in the reproductive tract (Sheldrick \& Flint, 1985; Ayad \& Wathes, 1989; Ayad et al., 1990a) which were seen to be most densely distributed in the endometrial epithelium of the uterus and the muscular wall of the oviduct (Ayad et al., 1990b). We have shown that circulating oxytocin increases oviduct muscle electromyographic activity during oestrus in cyclic ewes (Gilbert \& Wathes, 1991) and in oestradiol-treated anoestrous ewes (Ayad et al., 1990c), and suggest that endogenous oxytocin affects contractility in the oestrogen-dominated, non-pregnant reproductive tract of the ewe. The effect of this phenomenon on gamete transport and fertility remains to be investigated.

The blood sampling technique used for Exp. 2 has the advantage that animals were unrestrained and could be used for behavioural tests in relatively stress-free circumstances. This may be important since oxytocin has been shown to be a mediator of stress-induced ACTH secretion in the rat (Gibbs, 1986) although there is no direct evidence linking oxytocin release and stress in sheep. All experimental ewes were therefore housed in the experimental area for at least 5 days before blood sampling, and other companion ewes were in neighbouring pens throughout. Nevertheless, plasma cortisol measurements in future experiments would be useful to support the assumption of a low-stress environment. 
Wang et al. (1988) showed that blood loss in sheep equivalent to $1.5 \%$ of body weight over 15 min caused a dramatic rise in plasma arginine vasopressin (AVP) concentrations, but they provided no data for oxytocin. However, Kadekaro et al. (1988) indicated that a blood loss of $1 \cdot 3 \%$ of body weight over 5 min caused a 4-fold increase in plasma oxytocin concentrations and a 23 -fold increase in AVP. Accordingly, in the present experiments no more than $320 \mathrm{ml}$ blood $(0.6 \%$ of body weight) was taken from any ewe on the experimental day. Results for the 2 ewes from which plasma was assayed for AVP indicated that this rate of blood withdrawal did not impose a hypovolaemic stress on the ewes. Oxytocin concentrations measured from samples taken every $30 \mathrm{~min}$ throughout the day also showed no tendency to increase with blood removal. Water was, however, constantly made available during experimentation. The high specificity of the antisera from both assays indicates that interference and cross-reactivity between assays is highly unlikely.

The free flow of blood during continuous collection depended upon prior heparinization of ewes. An experiment investigating the effect of heparin on the plasma oxytocin concentrations in vitro (Gilbert, 1989) did not show any significant effect of added heparin to assay results.

In conclusion, we have shown that, although mean plasma oxytocin concentrations were low at oestrus in the ewe, a continuous blood sampling regimen was able to reveal the presence of significant short-duration pulses. The precise stimulus for this release remains unknown, but the presence of a ram markedly increased pulse frequency.

We thank Dr M. Foxcroft for performing the LH assay; Mrs S. Fennell for expert technical work; Mr R. Francis and his staff for care of the animals; and the Wellcome Trust and the AFRC for financial support.

\section{References}

Ayad, V.J. \& Wathes, D.C. (1989) Characterization of endometrial and myometrial oxytocin receptors in the non-pregnant ewe. J. Endocr. 123, 11-18.

Ayad, V.J., McGoff, S.A. \& Wathes, D.C. (1990a) Oxytocin receptors in the oviduct during the oestrus cycle of the ewe. J. Endocr. 124, 353-359.

Ayad, V.J., Guldenaar, S.E.F. \& Wathes, D.C. (1990b) Localization of oxytocin receptors in the uterus and oviduct of the oestrous ewe. J. Physiol. 426, 26P.

Ayad, V.J., Wathes, D.C., McGofi, S.A. \& Gilbert, C.L. (1990c) Comparison of the actions of oxytocin and $\left[\mathrm{Arg}^{8}\right]$-vasopressin on the EMG activity of the reproductive tract of oestrogen-treated anoestrous ewes. $J$. Reprod. Fert. Abstr. Ser. 4, 26.

Barowicz, T. \& Styczynski, H. (1972) Half-life of exogenous oxytocin in sheep under different physiological conditions. Acta Biol. Ser. Zool. 15, 105-112.

Carmichael, M.S., Humbert, R., Dixen, J., Palmisano, G., Greenleaf, W. \& Davidson, J.M. (1987) Plasma oxytocin increases in the human sexual response. $J$. clin. Endocr. Metab. 64, 27-31.

Debackere, M. \& Peeters, G. (1960) The influence of vaginal distension on milk ejection and diuresis in the lactating cow. Arch. Int. Pharmacodyn. Ther. 123, 462-471.

Debackere, M., Peeters, G. \& Tuyttens, N. (1961) Reflex release of an oxytocic hormone by stimulation of genital organs in male and female sheep studied by a cross-circulation technique. J. Endocr. 22, 321-334.

Flint, A.P.F. \& Sheldrick, E.L. (1983) Evidence for a systemic role for ovarian oxytocin in luteal regression in sheep. J. Reprod. Fert. 67, 215-225.

Flint, A.P.F., Forsling, M.L., Mitchell, M.D. \& Turnbull,
A.C. (1975) Temporal relationship between changes in oxytocin and prostaglandin $F$ levels in response to vaginal distension in the pregnant and puerperal ewe. J. Reprod. Fert. 43, 551-554.

Forsling, M.L. (1986) Regulation of oxytocin release. Current Topics in Neuroendocrinology 6, 19-53.

Foster, J.P. \& Crighton, D.B. (1974) Luteinizing hormone $(\mathrm{LH})$ release after single injections of synthetic LH-releasing hromone (LH-RH) in the ewe at three different reproductive stages and comparison with natural LH release at oestrus. Theriogenology 2, $87-100$.

Fox, C.A. \& Knaggs, G.S. (1969) Milk-ejection activity (oxytocin) in peripheral venous blood in man during lactation and in association with coitus. J. Endocr. 45, 145-146.

Fuchs, A.R., Cubile, L. \& Dawood, M.Y. (1981) Effect of mating on levels of oxytocin and prolactin in the plasma of male and female rabbits. J. Endocr. 90, 245-253.

Garcia-Villar, R., Schams, D., Alvinerie, M., Laurentie, M.P. \& Toutain, P.L. (1985) Activity of the genital tract and plasma levels of oxytocin and cortisol at the time of mating in the ewe. J. Endocr. 105, 323-329.

Gibbs, D.M. (1986) Vasopressin and oxytocin: hypothalamic modulators of the stress response: A review. Psychoneuroendocrinology 11, 131-140.

Gilbert, C.L. (1989) Oxytocin and the ovarian cycle in domestic ruminants. Ph.D. thesis, University of Bristol.

Gilbert, C.L. \& Wathes, D.C. (1991) The effect of oxytocin electromyographic (EMG) activity at oestrus in the ewe. J. Reprod. Fert., Suppl. 43, 314-35. 
Hawker, R.W., Roberts, V.S. \& Walmsley, C.F. (1959) Oxytocin and oxytocic substance in blood extracts before, and following, copulation in sheep. Endocrinology 64, 309-310.

Higa, T. \& Desiderio, D.M. (1989) Optimizing recovery of peptides from an octadecylsilyl (ODS) cartridge. Int. J. Peptide Protein Res. 33, 250-255.

Higuchi, T., Honda, K., Fukuoka, T., Negoro, H. \& Wakabayashi, K. (1985) Release of oxytocin during suckling and parturition in the rat. J. Endocr. 105, 339-346.

Hooper, S.B., Watkins, W.B. \& Thorburn, G.D. (1986) Oxytocin, oxytocin-associated neurophysin, and prostaglandin $F_{2} \alpha$ concentrations in the uteroovarian vein of pregnant and non-pregnant sheep. Endocrinology 119, 2590-2597.

Ivell, R., Brackett, K.H., Fields, M.J. \& Richter, D. (1985) Ovulation triggers oxytocin gene expression in the bovine ovary. FEBS Lett. 190, 263-267.

Jochle, W. (1975) Current research in coitus induced ovulation: a review. J. Reprod. Fert., Suppl. 22, 165-207.

Kadekaro, M., Summy-Long, J.Y., Terrell, M.L., Lekan, H., Gary, H.E. \& Eisenberg, H.M. (1988) The influence of baroreceptors on the secretion of vasopressin and oxytocin during haemorrhage in rats. Proc. 8th Int. Congr. Endocrinology, Hakone, Poster Abstr. 4.

Lamsa, J.C. \& McCracken, J.A. (1985) The effect of estrogen on the pulse frequency of oxytocin release from the brain of ovariectomised sheep. Biol. Reprod. 32 (Suppl. 1), 38 (Abstr. 2).

Mattioli, M., Galeati, G., Conte, F. \& Seren, E. (1986) Effect of $5 \alpha$-androst-16-en-3-one on oxytocin release in oestrous sows. Theriogenology 25, 399-403.

McCracken, J.A., Schramm, W., Manning, M. \& Robinson, A.G. (1984) Identification of episodic pulses of oxytocin in the peripheral blood of cyclic and ovariectomised sheep. Biol. Reprod. 30 (Suppl.), 154 (Abstr. 248).

McLeod, B.J., Haresign, W. \& Lamming, G.E. (1982) The induction of ovulation and luteal function in seasonally anoestrous ewes treated with small-dose multiple injections of Gn-RH. J. Reprod. Fert. 65, 215-221.

MeNeilly, A.S. \& Ducker, H.A. (1972) Blood levels of oxytocin in the female goat during coitus. $J$. Endocr. 54, 399. 406.

Merriam, G.R. \& Wachter, K.W. (1982) Algorithms for the study of episodic hormone secretion. Am. J. Physiol. 243 (Endocrinol. Metab. 6), E310-E318.

Mitchell, M.D., Kraemer, D.L., Brennecke, S.P. \& Webb, P. (1982) Pulsatile release of oxytocin during the oestrous cycle, pregnancy and parturition in sheep. Biol. Reprod. 27, 1169-1173.

Roberts, J.S. \& Share, L. (1969) Effects of progesterone and oestrogen on blood levels of oxytocin during vaginal distension. Endocrinology 84, 1076-1081.

Roberts, J.S., McCracken, J.A., Gavagan, J.E. \& Solof,, M.S. (1976) Oxytocin-stimulated release of prostaglandin $F_{2} \alpha$ from ovine endometrium in vitro: correlation with oestrous cycle and oxytocin-receptor binding. Endocrinology 99, 1107-1114.
Schams, D., Baumann, G. \& Leidl, W. (1982a) Oxytocin determination by radioimmunoassay in cattle II. Effect of mating and stimulation of genital tract in bulls, cows and heifers. Acta endocr., Copenh. 99, 218-223.

Schams, D., Lahlou-Kassi, A. \& Glatzel, P. (1982b) Oxytocin concentrations in peripheral blood during the oestrous cycle and after ovariectomy in two breeds of sheep with low and high fecundity. $J$. Endocr. 92, 9-13.

Seldinger, S.I. (1953) Catheter replacement of the needle in percutaneous arteriography. Acta radiol. 39, $368-376$.

Sheldrick, E.L. \& Flint, A.P.F. (1981) Circulating concentrations of oxytocin during the oestrous cycle and early pregnancy in sheep. Prostaglandins 22, 631-636.

Sheldrick, E.L. \& Flint, A.P.F. (1985) Endocrine control of uterine oxytocin receptors in the ewe. $J$. Endocr. 106, 249-258.

Taylor, P.L. (1987) Munro:- hormone-profile analysis. Zaristow software; Haddington, East Lothian, UK.

Todd, K. \& Lightman, S.L. (1986) Oxytocin release during coitus in male and female rabbits: effect of opiate receptor blockade with naloxone. Psychoneuroendocrinology 11, 367-372.

Van Demark, N.L. \& Hays, R.L. (1953) Effect of stimulation of the reproductive organs of the cow on the release of an oxytocin-like substance. Endocrinology $52,634-637$.

Vighio, G.H. \& Liptrap, R.M. (1986) Plasma concentrations of oxytocin, prostaglandin and ovarian steroids during spontaneous luteolysis in the cow. Dom. Anim. Endocrinol. 3, 209-215.

Wang, X.-M., Tresham, J.J., Coghlan, J.P., Congiu, M. \& Scoggins, B.A. (1988) Central effects of somatostatin and its analogues on response of plasma vasopressin to haemorrhage in sheep. Proc. 8th Int. Congr. Endocrinology, Hakone, Poster Abstr. 12.

Wathes, D.C. (1989) Oxytocin and vasopressin in the gonads. Oxford Rev. Reprod. Biol. 11, 226-283.

Wathes, D.C., Swann, R.W., Birkett, S.D., Porter, D.G. \& Pickering, B.T. (1983) Characterization of oxytocin, vasopressin and neurophysin from the bovine corpus luteum. Endocrinology 113, 693-698.

Wathes, D.C., Swann, R.W. \& Pickering, B.T. (1984) Variation in oxytocin, vasopressin and neurophysin concentrations in the bovine ovary during the oestrous cycle and pregnancy. J. Reprod. Fert. 71, 551-557.

Wathes, D.C., Guldenaar, S.E.F., Swann, R.W., Webb, R., Porter, D.G. \& Pickering, B.T. (1986) A combined radioimmunoassay and immunocytochemical study of ovarian oxytocin production during the periovulatory period in the ewe. J. Reprod. Fert. 78, 167-183.

Webb, R., Mitchell, M.D., Falconer, J. \& Robinson, J.S. (1981) Temporal relationships between peripheral plasma concentrations of oxytocin, progesterone and 13,14-dihydro-15-keto prostaglandin $F$ during the oestrous cycle and early pregnancy in the ewe. Prostaglandins 22, 443-454.

Received 11 June 1990 